\title{
Mycotoxin profiles of animal feeds in the central part of Thailand: 2015-2020
}

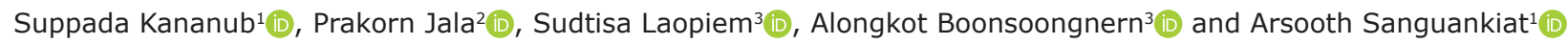

1. Department of Veterinary Public Health, Faculty of Veterinary Medicine, Kasetsart University, Kamphaeng Saen, Nakhon Pathom, Thailand; 2. Kamphaeng Saen Veterinary Diagnostic Center, Faculty of Veterinary Medicine, Kasetsart University, Kamphaeng Saen, Nakhon Pathom, Thailand; 3. Department of Farm Resources and Production Medicine, Faculty of Veterinary Medicine, Kasetsart University, Kamphaeng Saen, Nakhon Pathom, Thailand. Corresponding author: Arsooth Sanguankiat, e-mail: fvetass@ku.ac.th

Co-authors: SK: fvetsak@ku.ac.th,PJ: fvetpkj@ku.ac.th, SL: fvetsts@ku.ac.th, AB: fvetakb@ku.ac.th Received: 20-11-2020, Accepted: 05-02-2021, Published online: 23-03-2021

doi: www.doi.org/10.14202/vetworld.2021.739-743 How to cite this article: Kananub S, Jala $P$, Laopiem S, Boonsoongnern A, Sanguankiat A (2021) Mycotoxin profiles of animal feeds in the central part of Thailand: 2015-2020, Veterinary World, 14(3): 739-743.

\begin{abstract}
Background and Aim: Mycotoxin contamination in animal feeds is of considerable concern because it can affect animal health systems. As a result of contamination in the food chain, humans can indirectly come into contact with mycotoxins. The present study aimed to present mycotoxin contamination patterns in animal feeds from 2015 to 2020 and elucidate associations between the type of feed and the type of ingredient.
\end{abstract}

Materials and Methods: Data were summarized from the records of the Kamphaeng Saen Veterinary Diagnosis Center from 2015 to 2020, which comprised the analyses of aflatoxin (AFL), zearalenone (ZEA), T-2 toxin (T-2), fumonisin (FUM), and deoxynivalenol (DON) contamination in feed ingredients, complete feeds, and unclassified feeds. Descriptive statistics, Chi-squared tests, and Fisher's exact tests were used for data analysis.

Results: ZEA was prevalent in animal feeds. The prevalence of each mycotoxin was constant from 2015 to 2020. Approximately $20-30 \%$ of samples were positive for AFL and FUM. The highest contamination was ZEA, which was found in $50 \%$ of the samples, and the occurrence of T- 2 and DON was $<10 \%$. AFL significantly contaminated complete feeds more than feed ingredients. Feed ingredients were related to mycotoxin contaminations. The highest levels of AFL, FUM, and DON contamination occurred in 2017. The data in this year consisted mostly of soybean, corn, and rice bran.

Conclusion: The number of positive samples of all five mycotoxins was constant from 2015 to 2020, but the occurrence of ZEA was the highest. Mycotoxins in feedstuffs are significantly related to the type of feed and the type of ingredient.

Keywords: complete feeds, compound feeds, contamination, enzyme-linked immunosorbent assay, mycotoxin.

\section{Introduction}

Animal feeds and forages contain a wide range of contaminants and toxins. Contamination with mycotoxins, which are secondary metabolites produced by fungi present in forages, cereals, and compound feeds of livestock, is a global issue. Fungal contamination affects animal health, and hence the animal industry, by influencing the nutritional value and palatability of feed, and causes mycotoxicosis in animal [1-3]. The most economically important mycotoxins in terms of their prevalence and undesirable effects on animal performance are aflatoxin B1, deoxynivalenol (DON), zearalenone (ZEA), ochratoxin A, trichothecenes, and fumonisin B1 [4]. These mycotoxins are produced mainly by Aspergillus, Fusarium, and Penicillium, the primary fungi related to the contamination of food and animal feeds [5-7].

Copyright: Kananub, et al. Open Access. This article is distributed under the terms of the Creative Commons Attribution 4.0 International License (http://creativecommons.org/licenses/ by/4.0/), which permits unrestricted use, distribution, and reproduction in any medium, provided you give appropriate credit to the original author(s) and the source, provide a link to the Creative Commons license, and indicate if changes were made. The Creative Commons Public Domain Dedication waiver (http:// creativecommons.org/publicdomain/zero/1.0/) applies to the data made available in this article, unless otherwise stated.
As a result of contamination in the food chain, humans can indirectly contact the mycotoxin $[5,7,8]$. An adverse effect of consumption of toxins such as aflatoxin (AFL) is liver cancer in humans; it has also been associated with stunting and other health problems. The consumption of AFLs in high amounts by animals also results in severe, sudden onset of illness, and death [9]. There is evidence of chemical and biological alterations of mycotoxins by thermal modifications during processing; fungus-, plant-, or animal-derived metabolites of matrix-associated mycotoxins have increasingly been recorded in recent years, and they may contribute to overall mycotoxin exposure [10]. Several factors influence the growth of fungi and alter the nutritional requirements of animals, such as species, breed, sex, ration consumption, diet energy level, nutrient availability, temperature, air humidity, and animal health status. The occurrence of mycotoxins in each area might be different $[1,2,5,11]$. The profiles of mycotoxins in animal feeds are essential for the manufacturers to improve animal performance and products [12].

The aim of this study was to determine the mycotoxin profiles of animal feeds in Thailand, with data derived from a veterinary diagnostic laboratory 
in West Thailand from 2015 to 2020, and to elucidate the associations between the type of feed and type of ingredient.

\section{Materials and Methods \\ Ethical approval}

Ethical approval was not required for this study.

\section{Data collection}

The data in this study were summarized from records of the Kamphaeng Saen Veterinary Diagnostic Center from 2015 to 2020. All samples were analyzed by enzyme-linked immunosorbent assay (ELISA) from Romer $^{\circledR}$ Labs (Getzersdorf, Austria), and Neogen ${ }^{\circledR}$ Corporation (Lansing, Michigan, USA), according to the manufacturer's instructions. AgraQuant ${ }^{\circledR}$ AFL, AgraQuant $^{\circledR}$ ZEA Plus, and AgraQuant ${ }^{\circledR}$ Fumonisin $^{-}$ (FUM) ELISA tests by Romer ${ }^{\circledR}$ Labs were used to quantify the total amount of AFL, ZEA, and FUM; the ranges of detection were 4-40 ppb, 25-1000 ppb, and 250-5000 ppb, respectively. Veratox ${ }^{\circledR}$ T-s/HT-2 Toxin (T-2) and Veratox ${ }^{\circledR}$ Don $2 / 3$ from Neogen ${ }^{\circledR}$ Corporation were used to quantify the amount of T-2 and DON, with detection limits of 25-250 ppb and 500-6000 ppb, respectively.

\section{Statistical analysis}

The prevalence of mycotoxin contamination according to sampling year, type of sample, and type of feed ingredient was tabulated. Feed ingredients, complete feeds, and unclassified feeds were compared in this study. Ingredients such as rice bran, soybean, cassava chips, corn, rice, and unclassified ingredients were categorized by mycotoxin levels according to the permitted levels recommended in the previous studies $[1,13,14]$. Samples were identified as CS: Cassava chip, RI: Rice, RB: Rice bran, CO: Corn, and SB: Soybean, while other unidentified feed samples were called "other" for which identification was not available. From these studies, permitted levels in agricultural products are $20 \mathrm{ppb}$ of AFL, $100 \mathrm{ppb}$ of ZEA, $250 \mathrm{ppb}$ of T-2, $5000 \mathrm{ppb}$ of FUM, and $900 \mathrm{ppb}$ of DON. The independence between the appearance of mycotoxin and other factors groups was assessed using Pearson's Chi-squared test and Fisher's exact test by STATA software version 13.1 (StataCorp, College Station, TX, USA) [15]. $\mathrm{p}<0.05$ was considered statistically significant.

\section{Results}

This study included 3852 data entries from 2015 to 2020. The occurrence of mycotoxins and the level of detection in each year are shown in Table-1. The highest sample (893 records) was in 2015, while the lowest sample (243 records) was found in 2020 (with only 6 months data). Considering the mycotoxin tests performed during 2015 and 2020, the highest demand for testing was ZEA followed by AFL and FUM. Middle to low levels of contamination were found for all toxins. High-level contamination was found for AFL $(2.3 \%)$, while T-2 did not feature in high-level contaminations. Half of the ZEA samples (54.1\%) contained 25-1000 ppb. Low range contaminations of AFL, T-2, FUM, and DON were found in $71.7 \%$, $94.7 \%, 72 \%$, and $92.8 \%$ of samples, respectively (Table-1).

Table-2 presents mycotoxin levels based on samples in the detection range. Overall, the median of each toxin did not deviate in each year. The greatest variation was observed in FUM, for which the highest level was twice as likely as the lowest level. There were 2512 and 932 feed ingredients and complete feeds, respectively, whereas the unclassified group comprised 408 samples. The current study excluded the unclassified group because the type of feed could not be identified. The existence of AFL depended on the type of feed $(p<0.05)$. The incidence of AFL contamination in complete feeds was 5\% higher than that in feed ingredients (Figure-1).

The relationship between the contamination and the type of ingredient was significant $(\mathrm{p}<0.05)$. AFL was highly positive in corn and rice bran and "unclassified ingredient" samples. The ZEA contamination was higher than $60 \%$ in rice bran, soybean, and "unclassified ingredient" samples. About 15\% of unclassified feed was contaminated with T-2 and $<6 \%$ of the rest of the feed ingredients were contaminated with T-2. The highest occurrence of DON was in "unclassified ingredient" samples, which was 3 times higher than the contamination in cassava chips. FUM contaminated corn in up to $80 \%$ of samples (Figure-2). Less than $5 \%$ of feed ingredients and complete feeds were higher than the allowable levels in agricultural products; therefore, their relationship with other factors was not analyzed.

\section{Discussion}

The occurrence of mycotoxins in this study did not conform to other studies $[5,12,16]$. The mycotoxin most prevalent in this study was ZEA, which concurred with D'Mello [11]. Rodrigues et al. [14] indicated that the occurrence of FUM and type B trichothecenes

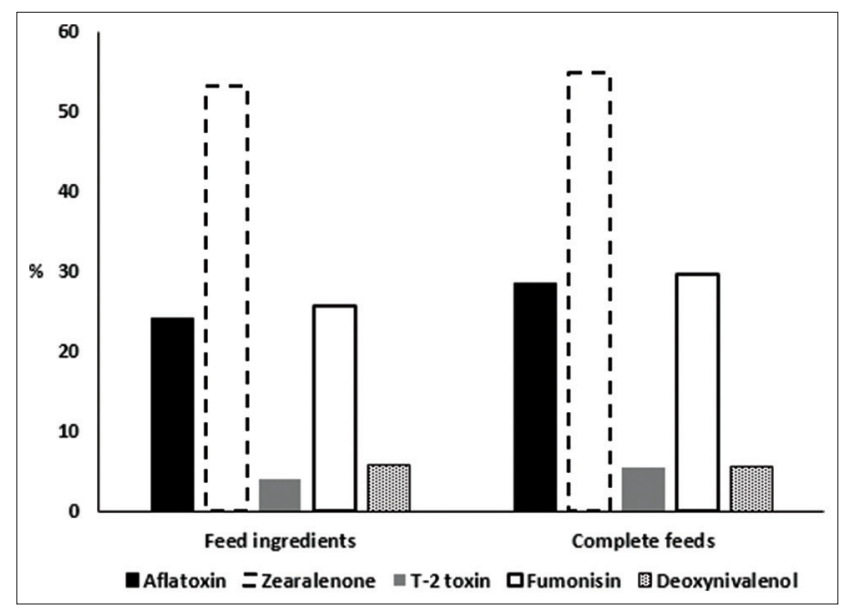

Figure-1: Prevalence of mycotoxin contamination in feed ingredients and complete feeds in the central part of Thailand from 2015 to 2020. 
Available at www.veterinaryworld.org/Vol.14/March-2021/25.pdf

Table-1: AFL, ZEA, T-2, FUM, and DON contamination in feed samples in the central part of Thailand from 2015 to 2020.

\begin{tabular}{|c|c|c|c|c|c|c|c|c|c|}
\hline \multirow[t]{2}{*}{ Mycotoxin } & \multirow[t]{2}{*}{ Total } & \multirow[t]{2}{*}{ Range } & \multicolumn{6}{|c|}{ No. of samples } & \multirow[t]{2}{*}{$\%$} \\
\hline & & & $\begin{array}{c}2015 \\
\left(n^{1}=893\right)\end{array}$ & $\begin{array}{c}2016 \\
(n=863)\end{array}$ & $\begin{array}{c}2017 \\
(n=841)\end{array}$ & $\begin{array}{c}2018 \\
(n=553)\end{array}$ & $\begin{array}{c}2019 \\
(n=459)\end{array}$ & $\begin{array}{c}2020 \text { (Jan. to June) } \\
(n=243)\end{array}$ & \\
\hline \multirow[t]{3}{*}{ AFL (ppb) } & 2564 & $<4$ & 404 & 431 & 401 & 258 & 223 & 121 & 71.68 \\
\hline & & $4-40$ & 206 & 125 & 124 & 89 & 88 & 35 & 26.01 \\
\hline & & $>40$ & 16 & 11 & 7 & 13 & 8 & 4 & 2.30 \\
\hline \multirow[t]{3}{*}{ Zearalenone (ppb) } & 2699 & $<25$ & 266 & 251 & 267 & 150 & 178 & 126 & 45.87 \\
\hline & & $25-1000$ & 330 & 410 & 332 & 195 & 159 & 34 & 54.09 \\
\hline & & $>1000$ & 0 & 1 & 0 & 0 & 0 & 0 & 0.04 \\
\hline \multirow[t]{3}{*}{ T-2 (ppb) } & 1829 & $<25$ & 372 & 432 & 404 & 225 & 199 & 100 & 94.70 \\
\hline & & $25-250$ & 28 & 31 & 31 & 6 & 1 & 0 & 5.30 \\
\hline & & $>250$ & 0 & 0 & 0 & 0 & 0 & 0 & 0.00 \\
\hline \multirow[t]{3}{*}{ FUM (ppm) } & 2294 & $<0.25$ & 330 & 375 & 371 & 283 & 234 & 68 & 72.41 \\
\hline & & $0.25-5$ & 108 & 146 & 145 & 89 & 42 & 68 & 26.07 \\
\hline & & $>5$ & 4 & 6 & 12 & 6 & 5 & 2 & 1.53 \\
\hline \multirow[t]{3}{*}{ DON (ppm) } & 719 & $<0.5$ & 150 & 98 & 166 & 107 & 102 & 44 & 92.77 \\
\hline & & $0.5-6$ & 18 & 15 & 13 & 3 & 0 & 2 & 7.09 \\
\hline & & $>6$ & 0 & 0 & 1 & 0 & 0 & 0 & 0.14 \\
\hline
\end{tabular}

${ }^{1} \mathrm{~N}=$ The total number of samples each year. AFL=Aflatoxin, $\mathrm{ZEA}=$ Zearalenone, $\mathrm{T}-2=\mathrm{T}-2$ toxin, FUM=Fumonisin, DON=Deoxynivalenol

Table-2: Mycotoxin levels based on the samples in the detection ranges in the central part of Thailand from 2015 to 2020.

\begin{tabular}{|c|c|c|c|c|c|c|}
\hline \multirow[t]{2}{*}{ Mycotoxin } & \multicolumn{6}{|c|}{ Median IQR ${ }^{1}(\min -\max )$} \\
\hline & 2015 & 2016 & 2017 & 2018 & 2019 & $\begin{array}{c}2020 \\
\text { (Jan. to June) }\end{array}$ \\
\hline AFL (ppb) & $\begin{array}{c}6.10-5 \\
(4-39.70)\end{array}$ & $\begin{array}{l}5.80-4.40 \\
(4-38.20)\end{array}$ & $\begin{array}{l}6.60-7.85 \\
(4-37.70)\end{array}$ & $\begin{array}{l}5.50-3.80 \\
(4-38.70)\end{array}$ & $\begin{array}{l}5.30-3.40 \\
(4-33.60)\end{array}$ & $\begin{array}{l}5.50-4.10 \\
(4-32.50)\end{array}$ \\
\hline ZEA (ppb) & $\begin{array}{c}49.20-49 \\
(25.10-477.50)\end{array}$ & $\begin{array}{c}43.10-35.20 \\
(25.10-459.8)\end{array}$ & $\begin{array}{l}44.20-38.60 \\
(25-598.90)\end{array}$ & $\begin{array}{c}39.3-27.8 \\
(25.10-879.60)\end{array}$ & $\begin{array}{l}40.80-28.20 \\
(25-324.80)\end{array}$ & $\begin{array}{c}36.50-15.10 \\
(25.10-124.40)\end{array}$ \\
\hline T-2 (ppb) & $\begin{array}{c}29.60-8.10 \\
(25.10-64.10)\end{array}$ & $\begin{array}{c}35.60-15.90 \\
(25.30-65.10)\end{array}$ & $\begin{array}{c}33-11.70 \\
(25.40-112)\end{array}$ & $\begin{array}{c}28.65-4.40 \\
(25.30-33.90)\end{array}$ & $N / A^{2}$ & N/A \\
\hline FUM (ppm) & $\begin{array}{c}0.62-0.73 \\
(0.25-4.07)\end{array}$ & $\begin{array}{c}1.01-1.55 \\
(0.25-4.72)\end{array}$ & $\begin{array}{c}1.17-1.59 \\
(0.25-4.85)\end{array}$ & $\begin{array}{c}1.10-1.22 \\
(0.25-4.49)\end{array}$ & $\begin{array}{c}0.65-0.73 \\
(0.25-3.39)\end{array}$ & $\begin{array}{c}0.85-1.01 \\
(0.26-3.81)\end{array}$ \\
\hline DON (ppm) & $\begin{array}{c}0.60-0.20 \\
(0.50-3.10)\end{array}$ & $\begin{array}{c}0.60-0.40 \\
(0.50-1.30)\end{array}$ & $\begin{array}{c}0.70-0.20 \\
(0.50-1)\end{array}$ & $\begin{array}{c}0.50-0.20 \\
(0.50-0.70)\end{array}$ & N/A & $\begin{array}{c}0.55-0.10 \\
(0.50-0.60)\end{array}$ \\
\hline
\end{tabular}

${ }^{1} \mathrm{IQR}=$ Interquartile range, ${ }^{2} \mathrm{~N} / \mathrm{A}=$ No observation or only one observation, $\mathrm{AFL}=$ Aflatoxin, $\mathrm{ZEA}=$ Zearalenone, $\mathrm{T}-2=\mathrm{T}-2$ toxin, FUM=Fumonisin, DON=Deoxynivalenol

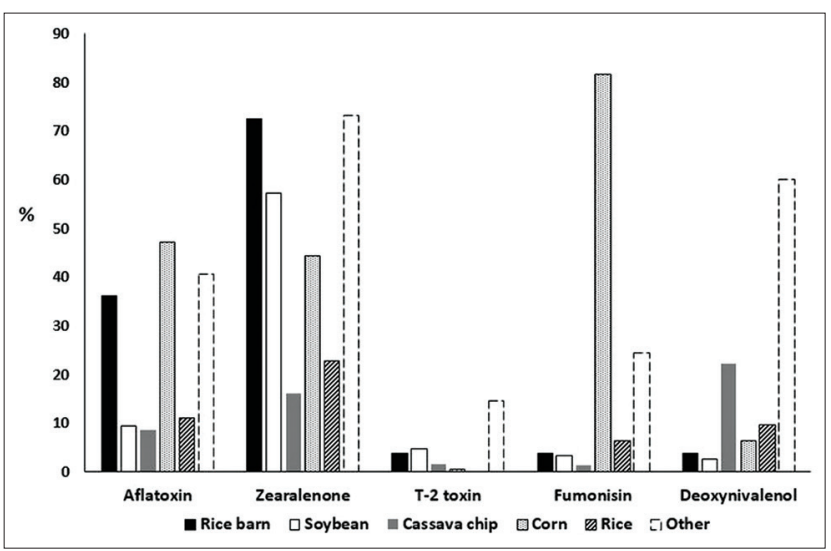

Figure-2: Percentage contamination as defined by feed ingredients ( $C S=$ Cassava chip, $\mathrm{RI}=$ Rice, $\mathrm{RB}=$ Rice bran, $\mathrm{CO}=$ Corn, $\mathrm{SB}=$ Soybean, Other=Ingredient identity not available).

was highest. A study in Thailand showed 100\% T-2 contamination in feed ingredients, but there was none in the Middle East and Africa, whereas the contamination in this study was approximately $10 \%$.
The prevalence of AFL and DON was higher than this study in the work of Charoenpornsook and Kavisarasai [6], Rodrigues et al. [14]. The T-2 contamination in the current study was similar to that of DON, but Cegielska-Radziejewska et al. [12] showed that the prevalence of DON was 5 times higher than that of T-2. DON and FUM contaminations in the samples were $59 \%$ and $64 \%$, respectively, in the study of Rodrigues and Naehrer [16] which differed from the current study. Contamination varied greatly between the studies since the existence of mycotoxins depends primarily on the study area [14]. Temperature and humidity are major causes for the difference in contamination incidence in each area and each year $[17,18]$. Appropriate storage conditions could prevent an increase in mycotoxin production [19].

The limits of detection reported by Charoenpornsook and Kavisarasai [6] based on their study in Thailand, were less than those in the current study, considering the high prevalence of AFL and DON, and $100 \% \mathrm{~T} 2$ contamination. Considering the 
occurrence of toxins in samples over the allowable limits, the incidence of contamination in the current study was lower than that in the study of Jala et al. [20], from the same area. However, our result is consistent with this study, that is, complete feeds were more contaminated than their ingredients.

The median of mycotoxin contamination throughout the study period was consistent. However, certain mycotoxins (AFL, FUM, and DON) were high in 2017. The contamination of AFL in the current study was related to the type of feed. Weather commonly influences the occurrence of mycotoxins in feedstuff; therefore, the kind of mycotoxin differed with time and area. The occurrence deviates from area to area or year to year $[3,5,12,16]$. Mold growth is chiefly related to temperature and humidity. Dry conditions increase the stress, leading to a decrease in plant immunity [5]. As a consequence of low immunity, crops could be sensitive to mycotoxin growth. Precipitation also stimulates the opportunity of infection by microorganisms $[1,5]$. Southeast Asia is, therefore, an area that has a high prevalence of AFL $[3,14]$.

Significant contamination of feed ingredients was similar to that reported in other studies $[13,21,22]$. Contamination with AFL, ZEA, and DON frequently occurs in feed ingredients. The most severe contaminant is DON followed by ZEA and AFL $[13,21]$. According to the preference of fungi for water, Fusarium mycotoxins (ZEA, DON, and FUM) are more likely to be found in feed ingredients [17]. However, some studies present different findings. Complete feeds are highly contaminated with Fusarium mycotoxins compared with the feed ingredients. This finding could be because complete feeds are prepared with ingredients that contain a high amount of Fusarium mycotoxins [23].

The levels of mycotoxins vary substantially depending on the type of feed [16]. AFL often exceeds the limit in corn or cottonseed [1]. Contamination with AFL occurs in corn and peanut cake, which are also cocontaminated with FUM $[11,22]$. Wu et al. [13] identified contamination of distillers dried grains, which is a popular animal feed ingredient with AFL, ZEA, and DON. There were no significant differences observed between the types of samples in these studies.

These results suggest that mycotoxin contamination in feedstuffs is problematic. The problems increase if the feed contains various mycotoxins [24]. Besides the animal health risks, humans are impacted by the consumption of animals that have consumed contaminated feedstuff $[3,6]$. The permitted levels in animal feeds are a measure to control contamination. It is useful for producers to avoid animal health risks. However, the limits vary from country to country $[1,12,25]$. Thailand specifies only the AFL level permitted in animal feeds, because of the severity of the toxin [18]. As a consequence of the mycotoxin contaminations in the present study, other permissible limits should also be legally indicated $[3,26]$. The present study is limited because the data were collected from available records. Therefore, the association analyses did not deal with all possible factors.

\section{Conclusion}

This study analyzed the prevalence of several mycotoxins from 2015 to 2020. High ZEA contaminations were evident in animal feeds. Contamination of $20-30 \%$ of samples with AFL and FUM was detected, whereas T-2 and DON contamination occurred in $<10 \%$ of samples. Mycotoxin contamination in feedstuffs is, therefore, significantly related to the type of feed or ingredient. Our findings are important for producers to ensure that they can select and use animal feeds that reduce risks to animal health.

\section{Authors' Contributions}

SK carried out the statistical analysis and drafted the manuscript. PJ, SL, and $\mathrm{AB}$ prepared and arranged the data. AS reviewed and edited the manuscript. All authors have read and approved the manuscript.

\section{Acknowledgments}

The authors sincerely thank the Kamphaeng Saen Veterinary Diagnostic Center, Faculty of Veterinary Medicine, Kasetsart University. The authors did not receive any funds for this study.

\section{Competing Interests}

The authors declare that they have no competing interests.

\section{Publisher's Note}

Veterinary World remains neutral with regard to jurisdictional claims in published institutional affiliation.

\section{References}

1. Guerre, P. (2016) Worldwide mycotoxins exposure in pig and poultry feed formulations. Toxins, 8(12): 350 .

2. Eskola, M., Kos, G., Elliott, C.T., Hajšlová, J., Mayar, S. and Krska, R. (2020) Worldwide contamination of food-crops with mycotoxins: Validity of the widely cited FAO estimate of 25\%. Crit. Rev. Food Sci. Nutr., 60(16): 2773-2789.

3. Gruber-Dorninger, C., Jenkins, T. and Schatzmayr, G. (2019) Global mycotoxin occurrence in feed: A ten-year survey. Toxins, 11(7): 375.

4. Magnoli, A.P., Poloni, V.L. and Cavaglieri, L. (2019) Impact of mycotoxin contamination in the animal feed industry. Curr. Opin. Food Sci., 29: 99-108.

5. Farkas, J., Beczner, J. and Mohácsi-Farkas, C.S. (2011) Potential impact of climate change on the risk of mycotoxin contamination of agricultural products in Southeast Central Europe. Acta. Univ. Sapientiae, 4: 89-96.

6. Charoenpornsook, K. and Kavisarasai, P. (2006) Mycotoxins in animal feedstuffs of Thailand. KMITL Sci. Technol. J., 6(1): 25-28.

7. Yiannikouris, A. and Jouany, J.P. (2002) Mycotoxins in feeds and their fate in animals: A review. Anim. Res., 51(2): 81-99.

8. Mngadi, P.T., Govinden, R. and Odhav. B. (2008) Co-occurring mycotoxins in animal feeds. Afr. J. Biotechnol., 7(13): 2239-2243. 
9. Atherstone, C., Grace, D., Lindahl, J.F., Kang'ethe, E.K. and Nelson, F. (2016) Assessing the impact of aflatoxin consumption on animal health and productivity. Afr. J. Food Nutr. Sci., 16(3): 10949-10966.

10. European Food Safety Authority. (2014) Scientific opinion on the risks for human and animal health related to the presence of modified forms of certain mycotoxins in food and feed. EFSA J., 12(12): 107.

11. D'Mello, J.P.F. (2004) Contaminants and toxins in animal feeds. FAO animal production and health paper. In: Assessing Quality and Safety of Animal Feeds. FAO, Rome, Italy. p152.

12. Cegielska-Radziejewska, R., Stuper, K. and Szablewski, T. (2013) Microflora and mycotoxin contamination in poultry feed mixtures from western Poland. Ann. Agric. Environ. Med., 20(1): 30-35.

13. Wu, L., Li, J., Li, Y., Li, T., He, Q., Tang, Y., Liu, H., Su, Y., Yin, Y. and Liao, P. (2016) Aflatoxin B 1, zearalenone and deoxynivalenol in feed ingredients and complete feed from different provinces in China. J. Anim. Sci. Biotechnol., 7(1): 63.

14. Rodrigues, I., Handl, J. and Binder, E.M. (2011) Mycotoxin occurrence in commodities, feeds and feed ingredients sourced in the Middle East and Africa. Food Addit. Contam. Part B Surveill., 4(3): 168-179.

15. StataCorp. (2013) Stata Statistical Software: Release 13. StataCorp LP, College Station, Texas.

16. Rodrigues, I. and Naehrer, K. (2012) A three-year survey on the worldwide occurrence of mycotoxins in feedstuffs and feed. Toxins, 4(9): 663-675.

17. Golob, P. (2007) On-Farm Mycotoxin Control in Food and Feed Grain. FAO, Rome, Italy. p27.

18. Tulayakul, P. and Sugita-Konishi, Y. (2017) Mycotoxin contamination in foodstuffs and feeds-health concerns in Thailand. Jpn. J. Vet. Res., 65(3): 173-183.

19. Mongkon, W., Sugita-Konishi, Y., Chaisri, W. and Suriyasathaporn, W. (2017) Aflatoxin B1 contamination of dairy feeds after storage in farm practice in tropical environment. Biocontrol. Sci., 22(1): 41-45.

20. Jala, P., Sanguankiat, A., Tulayakul, P., Laopiem, S. and Ratanavanichrojn, N. (2016) Mycotoxins in feedstuffs in Thailand-laboratory reports in the years 2010-2014. In: Proceedings of $54^{\text {th }}$ Kasetsart University Annual Conference: Plants, Animals, Veterinary Medicine, Fisheries, Agricultural Extension, and Home Economics, Bangkok. p609-615.

21. Ma, R., Zhang, L., Liu, M., Su, Y.T., Xie, W.M., Zhang, N.Y., Dai, J.F., Wang, Y., Rajput, S.A., Qi, D.S. and Karrow, N.A. (2018) Individual and combined occurrence of mycotoxins in feed ingredients and complete feeds in China. Toxins, 10(3): 113 .

22. Akinmusire, O.O., El-Yuguda, A.D., Musa, J.A., Oyedele, O.A., Sulyok, M., Somorin, Y.M., Ezekiel, C.N. and Krska, R. (2019) Mycotoxins in poultry feed and feed ingredients in Nigeria. Mycotoxin Res., 35(2): 149-155.

23. Kim, D.H., Lee, I.H., Do, W.H., Nam, W.S., Li, H., Jang, H.S. and Lee, C. (2014) Incidence and levels of deoxynivalenol, fumonisin, and zearalenone contaminants in animal feeds used in Korea in 2012. Toxins, 6(1): 20-32.

24. Flores-Flores, M.E., Lizarraga, E., de Cerain, A.L. and González-Peñas, E. (2015) Presence of mycotoxins in animal milk: A review. Food. Control., 53: 163-176.

25. Alvarado, A.M., Zamora-Sanabria, R. and GranadosChinchilla, F. (2017) A focus on aflatoxins in feedstuffs: Levels of contamination, prevalence, control strategies, and impacts on animal health. In: Abdulra'Uf, L., editor. Aflatoxin-Control, Analysis, Detection and Health Risks. Intech, London. p116-152.

26. Anukul, N., Vangnai, K. and Mahakarnchanakul, W. (2013) Significance of regulation limits in mycotoxin contamination in Asia and risk management programs at the national level. J. Food Drug Anal., 21(3): 227-241. 